\title{
Voltage Profile Improvement with Combined UPFC and IPFC Facts Devices: A Review
}

\author{
Violet Kaswii ${ }^{*}$, Michael J. Saulo² \\ 1Department of Electrical and Electronic Engineering, Jomo Kenyatta University of Agriculture and \\ Technology, P.O. Box 62000-00200, Juja, Kenya; ${ }^{2}$ Department of Electrical Engineering, Technical \\ University of Mombasa, P.O. Box 90420 - 80100, Mombasa, Kenya \\ ${ }^{*}$ Corresponding author: violetkavindu@gmail.com
}

\begin{abstract}
$\mathrm{T}$ The interline power flow controller (IPFC) and the unified power flow controller (UPFC) are both advanced types of flexible AC transmission systems (FACTS). These devices can provide the power system with control of voltage, and that of real and reactive power. This paper reviews the literature on UPFC and IPFC FACTS devices in voltage control and covers two main areas of research (i) voltage control using FACTS devices, and (ii) UPFCs / IPFCs and their applications in power systems. FACTs devices are applied in modern power system networks for the purpose of voltage control while at the same time providing enhanced power system stability. Research has shown that their benefits in the long run outweighs their high cost especially when they are optimally sized and located in the power network. Moreover, in the planning of power transmission systems, a Multi-Criteria Decision Making (MCDM) technique can help in the incorporation of both the costs and technical viability. This approach provides techno-economic optimization and at the same time meeting environmental criteria.
\end{abstract}

Key Words: Unified power flow controller, Interline power flow controller, Multi-criteria decision-making technique, Power system simulator for engineers

\section{Introduction}

Power systems are operated at a substantially constant voltage for the satisfactory operation of both transmission and distribution equipment. Large variations in voltage often cause errors in operation, malfunctioning and performance deterioration of equipment connected to the power system (Kundur, 1993). Voltage variation in power system is often caused by changes in load, generation and network structure. In transmission system operation, continuous monitoring of voltage is done to compensate for changes that may occur within the power system. Keeping voltages in a power system within specified limits is challenged by load variations which cause variation in reactive power requirements, thus necessitating the need for special devices placed at different locations in the system as reactive power cannot be transmitted. Proper coordination of reactive power control in power systems is therefore a major challenge in power system engineering (Igbinowa et al., 2018).
Voltage control is achieved by control of reactive power flow, and its production and absorption in the power system. Generators in the power system provide basic voltage control alongside line reactance compensators, regulating transformers and shunt compensators that act as sources and sinks of reactive power. Synchronous condensers provide active compensation offering benefits to weak dynamic electrical grids as they do not act as sources of harmonics despite the fact that they have higher losses and slower response time compared to power electronic devices (Nashawati, 2013). Shunt reactors compensate for the effects of line compensation (Igbinowa et al., 2018) thus improving the voltage profile. Magnetic core reactors found in the Kenya power system are prone to magnetic inrush currents and cause challenges in design of protection schemes (Arthit Sode-Yome (2014). Shunt capacitors supply reactive power and boost local voltages (Igbinowa et al., 2018). Their reactive power output is however proportional to the square of voltage indicating a low output for low voltages further escalating the voltage problem (Hassan \& Ahmed, 2018). Series 
compensators compensate for reactive compensation of the line (Igbinowa et al., 2018) thus improving system stability and load division in transmission lines. This equipment described above are the traditional compensating devices found in power systems that were established years back. The Kenya power system is currently composed of reactor banks and capacitor banks.

Flexile AC Transmission System devices (FACTS) have gained popularity in voltage control due to their flexibility and fast response. These devices use power electronic components to improve controllability of the power system components. Otherwise, these devices operate much like their predecessors as described above. Such controllers include Static Synchronous Compensators (STATCOM), Thyristor Controlled Series Capacitor (TCSC), Static Series Synchronous Compensator (SSSC), and Static Var Compensator (SVC) (Narain \& Srivastava, 2015). The UPFC and IPFC can be described as some of the most versatile FACTs devices with UPFCs combining the functions of STATCOM, Thyristor switched capacitor and Thyristor-controlled reactor (Narain \& Gyugyi, 2000).

\section{Voltage Control with FACTS Devices}

With the growing demand for electricity in developing countries, power systems have become more interconnected and hence complex. This has necessitated great effort to improve power utilization and reliability. The dynamics of distribution of load and generation have caused a situation of some of the transmission lines being overloaded while others are under loaded creating problems with the voltage profile. In order to control voltage, reactive power needs to be controlled. Flexile AC Transmission System devices (FACTS) are capable of providing voltage control as well as power system transient stability improvement. Several categories of FACTS controllers exist (Narain \& Gyugyi, 2000) including series controllers, series-series controllers, shunt controllers, and series-shunt controllers.

Series controllers are mainly either capacitor banks or reactor banks that inject voltages in series with the transmission lines. These controllers may also be power electronic-based variable sources that may give or take reactive power from the power system. The most common series controller the TCSC provides variable capacitive reactance and is therefore most suited when increasing damping that is often a key component in interconnecting large power systems (Short, 2004). Shunt controllers are similar to series controllers but they inject current in the power system while series controllers inject voltage. The most common of these controllers are STATCOM, Static Var Controllers (SVC) and Thyristor Controlled Reactors (TCR). The TCR, formed by two opposite facing thyristors limit voltage rise in lightly loaded lines (Hassan \& Ahmed, 2018). The SVC is however more popular in HV systems to improve system stability and reduce technical losses. The SVC being able to absorb and generate a reactive power can prevent voltage rise and sag. The STATCOM device while being capable of providing both the functions of SVC and TCR, it improves transient stability of the power system (Short, 2004). The combined FACTS devices are capable of providing series-series or series-shunt compensation and include such devices as IPFC and UPFC which are the subject of this paper.

\section{UPFC and IPFC FACTS Devices in Voltage Control}

The UPFC (Fig. 1), a combination of series-shunt converters is one of the most versatile compensators combining the functions of the STATCOM, TSC and TCR (Garg \& Kumar, 2013; Vishad \& Vinod, 2016), achieving its purpose by injecting a voltage in series with the transmission line. As a series-series converter the IPFC provides control of a number of transmission lines at a time in a substation (Gyqyi et al., 1995).

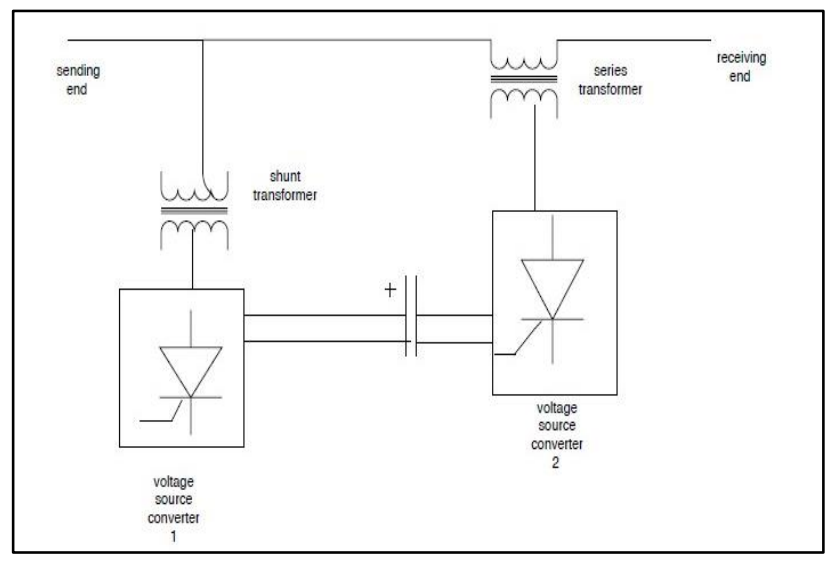


Figure 1. Basic structure of UPFC device

In addition to controlling the voltage magnitude in power systems, the UPFC has the added advantage of controlling the phase angle and line impedance (Vishad \& Vinod, 2016). It ensures that faster steady state is achieved due to its fast response capability and thus enhances transient stability in the power system. The performance of the UPFC under different system conditions was studied using a 2machine system to establish its effect on the reactive power versus real power characteristic at varying angles of transmission and compared to that of the TCSC (Han et al., 2017). The UPFC is indicated to provide simultaneous, real-time control of all transmission voltage, line impedance and phase angle while providing flexibility for ac power transmission control often only achievable with HVDC. The TCSC however, is seen to only control capacitive impedance thereby affecting only the magnitude of current flowing in transmission line. In the Korea power system, generation is mostly in coastal areas while loads are in inland metropolitan areas; the UPFC is installed to increase transmission line capacity and reduce system losses by controlling the power flow (Omoroguiywa \& Onohaebi, 2015).

The IPFC, which is an inverter-based FACTS device, employs the voltage-sources dc to ac inverter to compensate for a multi-transmission line system and has the capability to equalize real and reactive power hence enhancing utilization of transmission lines. An analysis of IPFC in the Nigerian $330 \mathrm{kV}$ network was conducted in a study (Natalia \& Santos, 2011) that involved locating the IPFC during normal and overload conditions using GA, concluding that with the increased cost of building generation stations, transmission lines and way leave acquisition costs, there was need to further their research into including such devices into their transmission networks. For the steadystate analysis of power systems with IPFCs, challenges may occur due to lack of suitable models to conduct such studies. Models that can be used with traditional power flow algorithms have been developed (Gyugyi, 1995). The principle operation of the IPFC is represented in Fig. 2 below (Singh, 1993).

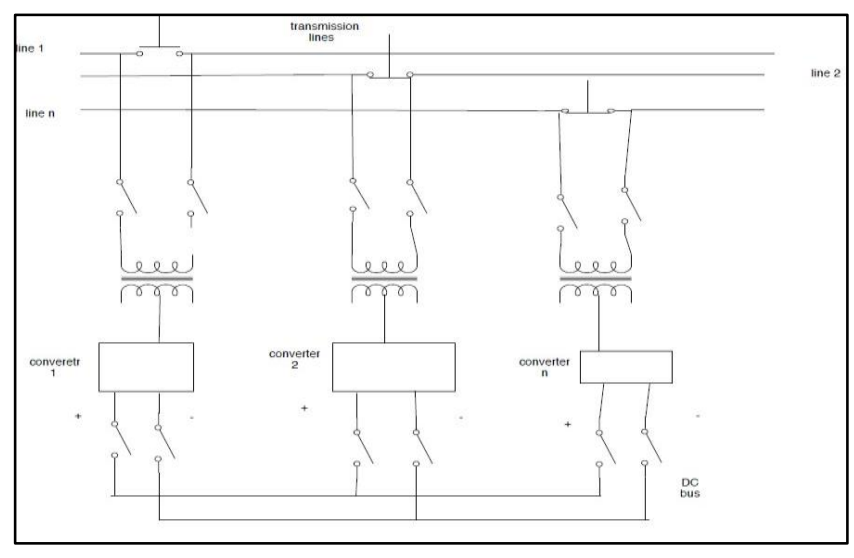

Figure 2. Basic structure of IPFC device

\section{Genetic Algorithm in Power Systems}

FACTS devices are important as power system controllers but capital intensive and as such their sizes and locations have to be carefully optimized to ensure maximum utilization. Genetic Algorithm (GA) is an optimization technique that is relevant to power systems. This is due to its robustness in finding optimal solutions and the ability to find a near optimal solution while avoiding the integer problem and the challenge of being caught up by a local minimum solution often associated with other optimization algorithms. Optimal settings have been obtained for minimum transmission loss on using GA to optimal reactive power dispatch (Bhattacharyya \& Goswami, 2011). Using one genetic operation like simple mutation, GA is explored in optimal power flow giving fast solutions to minimizing fuel costs and keeping generators within secure limits. A solution to power system congestion problem can be achieved by the use of UPFCs when they are optimally located using the GA thus increasing the power systems load ability (Orero, 1996). Generator scheduling is often constrained by ramp rates, an enhanced GA is expected to provide good unit schedules for medium-sized power system by ensuring that the fitness function can differentiate between bad and good solution thus providing accurate and feasible solutions (Whester, 2017).

\section{Conclusion}

This review paper contains a brief description of the essential features of UPFC and IPFC in the improvement of voltage profile. To protect power 
system equipment, power system voltages and phase angles should be kept within specified ranges. In Kenya, this value is taken to be between $\pm 5 \%$ for planning purposes. FACTs devices are applied in modern power system networks for the purpose of voltage control while at the same time providing enhanced power system stability. Research has shown that their benefits in the long run outweighs their high cost. Moreover, to optimize on their cost it is important to optimally select their sizes, and location. In the planning of power transmission systems, Multi-Criteria Decision Making (MCDM) technique can help in the incorporation of both the costs and technical viability. This approach provides techno-economic optimization and at the same time meeting environmental criteria.

\section{Acknowledgement}

The authors would like to thank the Department of Electrical and Electronic Engineering, Jomo Kenyatta University of Agriculture and Technology for the support provided during the study and final production of this publication.

\section{References}

Arthit Sode-Yome, N.M. (2014). Comparison of shunt capacitor, SVC and STATCOM in voltage stability margin enhancement. International Journal of Electrical Engineering and Education 41(1): 158-171

Bhattacharyya, A.B. \& Goswami, S.K. (2011). Optimal placement of FACTs devices by genetic algorithm for increased load ability of a power system. International Journal of Electrical and Computer Engineering 5(3): 1$12 \mathrm{pp}$

Garg, K.S. \& Kumar, V. (2013). Unified Power Flow Controller (FACTS Device): A review. International Journal of Engineering Research 3(4): 1430-1435

Gyugyi, L. (2016). Advanced solutions in power systems: HVDC FACTs and Artificial intelligence

Hassan, A.N. \& Ahmed, A.M. (2018). A literature review on the Unified Power Flow Controller UPFC. International Journal of
Computer Applications (0975-8887) 182(12) 1$8 \mathrm{pp}$

Han, L., Jianbo, Y., Lin, Z. \& Binbin, D. (2017). Enhancement of power system performance with UPFC under steady and dynamic conditions. ECAE $2^{\text {nd }}$ International Conference on Electrical, Control and Automation Engineering (ECAE 2017)

Igbinowa, F.O., Ghaeth, F., Ibrahim, A., Zdenek, M. \& Tlusty, J. (2018). Modeling and simulation of the anticipated effects of the synchronous condenser on an electric power network with participating wind plants. Sustainability: $3-5$

Kundur, P. (1993). Power system stability and control, McGraw Hill, British Colombia

Nashawati, E. (2013). Impacts of Shunt Reactors on Transmission

Narain, A. \& Srivastava, S.K. (2015). An overview of facts devices used for active power compensation techniques. International Journal of Engineering Research \& Technology 4(12): 81-85

Narain, H., \& Gyugyi, L. (2000). Understanding FACTS, concepts and technology of flexible AC transmission systems, IEEE Press

Natalia, O.D.V.F.P., \& Santos, M.R. (2011). Use of interline power flow controller model for power flow analysis. International Conference on Advances in Energy Engineering

Omoroguiywa, E. \& Onohaebi, S.O. (2015). Optimal location of IPFC in Nigeria $330 \mathrm{KV}$ integrated power network using genetic algorithm technique. International Journal of Electrical and Electronic Engineering 4(1): 1$8 \mathrm{pp}$

Orero, S. (1996). A genetic algorithm for generator scheduling in power systems

Short, T.A. (2004). Electrical power distribution handbook, Boca: CRC

Singh, S. (1993). Optimal reactive power dispatch using genetic algorithm, IEEE $3^{\text {rd }}$ International Symposium of Electricity Distribution and Energy management: 464469pp

Vishali, M.M. \& Vinod, C. (2016). Study of power system performance with interline power flow controller by using software and Lab 
prototype. International Research Journal of Engineering and Technology 3(4) 1888-1893pp

Whester, J.A. (2017). Multicriteria decision making for reactive power compensation in distribution systems. European Computing Conference, Brazil

Gyqyi, L. (1995). The Unified Power Flow Controller: A new approach to power transmission control. IEEE Transactions on Power Delivery 10(2) 1085-1097pp 